\title{
Paths from Spiritual Support to College Self-Efficacy in Southeastern Christian and Southeastern Public University Students
}

\author{
Mollie Dianne Kaye Carter*
}

* Department of Psychology, Asbury University, Wilmore, KY, United States.

Email: mollie.carter@asbury.edu

Article Info

Received: November 30, 2021

Revised: January 31, 2022

Accepted: February 5, 2022

$10.46303 / j$ jcsr.2022.2

\section{How to cite}

Carter, M. D. K. (2022). Paths from Spiritual Support to College SelfEfficacy in Southeastern Christian and Southeastern Public University Students. Journal of Curriculum Studies Research, 4(1), 1-17 https://doi.org/10.46303/icsr.2022.2

\section{Copyright license}

This is an Open Access article distributed under the terms of the Creative Commons Attribution 4.0 International license.

https://creativecommons.org/licenses/by/4.0/

\begin{abstract}
Using a modified portion of Lent's (2004) normative model of life satisfaction, this study assessed the role spiritual models play in Southeastern Christian university students' and Southeastern public university students' developing traits of spirituality, mindfulness, forgiveness, and hope, and the associations these traits had with college self-efficacy. Additionally, this study proposed perspectivetaking as a moderator of the association between environmental support from spiritual models and spirituality, mindfulness, forgiveness, and hope, such that college students high in perspective-taking would understand and internalize traits of models rather than only imitating the spiritual practices of the model. Participants $(n=384)$ in this one-time survey study were recruited from a public, urban university and a private, Christian university. Results of the moderated mediation paths show spirituality, mindfulness, forgiveness, and hope mediated the association between environmental support from spiritual models and college self-efficacy, but perspective-taking did not moderate associations from environmental support from spiritual models to the mediators. These findings supported the modified portion of Lent's (2004) normative model of life satisfaction which states that environmental support, including support given by spiritual models, enhanced the development of healthy traits such as spirituality, mindfulness, forgiveness, and hope. In turn, the healthy traits were associated with increased college self-efficacy.

\section{KEYWORDS}

Christian; university; Southeastern; spiritual modeling; college selfefficacy; perspective-taking. 


\section{INTRODUCTION}

Robert Lent's (2004; Lent et al. 2007) normative model of life satisfaction suggests environmental support is bi-directionally associated with positive affect and personality traits, which in turn are associated with increased self-efficacy. Lent's model excludes environmental support provided by spiritual models, whose influence may promote growth of spiritual traits. Spiritual models may be more readily available to students in Southeastern Christian universities than Southeastern public universities, and it is unknown how support from spiritual models impacts self-efficacy in college. Positive affect and the Big Five personality traits are known antecedents and mediators in the path from environmental support to self-efficacy (Lent 2004; Lent et al. 2007), but it is unknown if spiritual traits mediate the path from environmental support from spiritual models to college self-efficacy (Solberg et al. 1993). Four malleable spiritual traits that can be learned through the influence of others are spirituality, mindfulness, forgiveness, and hope (Davidson, Feldman, and Margalit 2012; Kiken et al. 2015; Luskin, Ginzburg, and Thoresen 2005; Oman et al. 2007; Oman et al. 2009). Each of these spiritual traits are correlated with forms of self-efficacy (Duffy and Lent 2008; Keye and Pidgeon 2013; Macaskill and Denovan 2013), pointing toward a path from environmental support from spiritual models to the four spiritual traits, which in turn may be associated with college selfefficacy.

\section{The Current Study}

The current study sought to determine whether group differences exist in college self-efficacy, spiritual modeling, spirituality, mindfulness, forgiveness, hope, and perspective-taking between a Southeastern Christian university and a Southeastern public university. Further, the current study focused on three groups of variables proposed by Lent and colleagues (Lent 2004; Lent et al. 2007): environmental support from spiritual models, positive traits, and college self-efficacy. A moderated mediation path model was fit to assess the hypotheses that (1) environmental support from spiritual models would be associated with college self-efficacy; (2) the relationship between environmental support from spiritual models and college self-efficacy would be mediated by spirituality, forgiveness, mindfulness, and hope; (3) perspective-taking would moderate the path from environmental support from spiritual models to the mediators, such that the relationship from environmental support from spiritual models to the mediating traits would be stronger among people with good perspective-taking.

\section{Participants}

A total of 384 undergraduate college students (Christian $90.1 \%$, atheist/agnostic $6.8 \%$, other faith tradition, $2.3 \%$, Muslim $0.5 \%$, and Buddhist $0.3 \%$ ) participated in the study from two Southeastern universities; One hundred eighty-eight from a public university, and 196 undergraduate students participated from a private, Christian university. 


\section{Measures}

\section{Environmental support from spiritual models}

Environmental support from spiritual models was measured using the Religious/Spiritual Organization and Famous and/or Divine Persons subscales of the Useful Exemplar scale of the Spiritual Modeling Inventory of Life Environments (SMILE; Oman et al. 2009; $\alpha=.89$ ). Test-retest reliability had been demonstrated for the community and prominent model subscales $(r=.74, r$ $=.78$, respectively).

\section{Spirituality}

Spirituality was measured using the self-report form of the Assessment of Spiritual Transcendence and Religious Practice Short form (ASPIRES; Piedmont et al. 2008). Psychometric properties of the spiritual transcendence and religious index demonstrated good reliability in the current study for the scales of spiritual transcendence $\alpha=.71$, religious index, $\alpha=.84$, and total scores, $\alpha=.79$.

\section{Mindfulness}

Mindfulness was measured using the Cognitive and Affective Mindfulness Scale - Revised (CAMS-R; Feldman et al. 2007). Good reliability for the scale was demonstrated in the current study $\alpha=.77$.

\section{Forgiveness}

Forgiveness was measured using the 18-item Heartland Forgiveness Scale (HFS; Thompson et al. 2005) which had been validated for college students $(\alpha=.83)$ with good reliability demonstrated in the current study, $\alpha=.77$.

\section{Hope}

Hope was measured with The Hope Scale (Babyak et al. 1993), consisting of 12 items on an 8point Likert scale. Good reliability for the hope scale was demonstrated in the current study, $\alpha$ $=.85$.

\section{Perspective-taking}

Perspective taking was measured with the 7-item Perspective-Taking subscale of the Interpersonal Reactivity Index (Davis 1983). Good reliability of the scale was demonstrated in the current study, $\alpha=.78$

\section{College self-efficacy}

The College Self-Efficacy Inventory (Solberg et al., 1993) was used to measure college selfefficacy. Good reliability for the scale was demonstrated for the current study, $\alpha=.92$.

\section{RESULTS AND ANALYSIS}

\section{Descriptive Statistics and Correlation Analyses}

A series of independent samples t-tests were conducted to assess differences in average scores on each of the independent, mediator, moderator, and dependent variables between the students enrolled at the public university and the students enrolled the private university 
According to Levene's test for homogeneity of variances, equal variance could not be assumed when comparing environmental support from spiritual models across institutions $(F=20.06, p$ $<.001)$. An unequal variances t-test indicated significant difference existed in environmental support from spiritual models between the public university $(M=71, S D=14.65)$ and the private university $(M=74.85, S D=8.87)$ groups, $t(277.89)=-3.01, p=.003$, with a small effect size $\left(d_{s}=\right.$ .32; Cohen, 1988). Similarly, equal variances could not be assumed between the groups on spirituality $(F=12.25, p=.001)$. An unequal variances t-test indicated a significant difference in spirituality scores between the public university $(M=50.29, S D=10.35)$ and the private university $(M=55.63, S D=8.35)$ groups, $t(333.22)=-5.48, p<.001$ with a moderate effect size $\left(d_{s}=.57\right)$. Thus, the sample from the private university reported significantly higher support from spiritual models and spirituality.

Equal variances were assumed between groups on mindfulness $(F=1.95, p=.16)$. A pooled t-test indicated no difference in the mindfulness scores between the public university $(M=31.22, S D=5.99)$ and the private university $(M=31.28, S D=5.40)$ groups $t(378)=-.09, p=$ .93. Equal variances were assumed between the groups on forgiveness $(F=2.71, p=.10)$. A pooled t-test showed no difference in the forgiveness scores between the public university $(M$ $=85.31, S D=15.97)$ and the private university $(M=83.50, S D=8.09)$ groups, $t(377)=1.16, p=$ .25. Equal variances were assumed for group comparisons for hope scores $(F=.12, p=.73)$. The pooled t-test showed there was no difference in hope scores between the public university $(M$ $=49.41, S D=8.14)$ and the private university $(M=48.01, S D=8.09)$ groups, $t(379)=1.67, p=.10$.

Equal variances were assumed for perspective-taking between the groups $(F=1.49, p=$ .22). A pooled t-test showed there was a significant difference in perspective-taking scores between the public university $(M=23.09, S D=5.19)$ and the private university $(M=19.37, S D=$ 4.09) groups, $t(377)=7.17, p=.001$ with a moderate effect size $\left(d_{s}=.74\right)$. Participants from the public university reported significantly higher perspective-taking than participants from the private university. Equal variances were assumed between the groups for college self-efficacy $(F=1, p=.32)$. A pooled t-test showed there was a significant difference in college self-efficacy scores between the public university $(M=133.06, S D=32.24)$ and the private university $(M=$ $142.93, S D=30.38)$ groups, $t(370)=-3.04, p=.003$ with a small effect size $\left(d_{s}=.32\right)$. Participants from the private university reported significantly higher college self-efficacy than participants from the public university.

Table 1 summarizes the descriptive statistics and correlations for each variable. In support of hypothesis one, Spiritual modeling $(M=72.81, S D=12.14)$ was significantly and positively associated with college self-efficacy $(M=138.47, S D=31.41, r=.24, p<.01)$. 
Table 1. Descriptives and correlations

\begin{tabular}{|c|c|c|c|c|c|c|c|}
\hline Variable & $M(S . D)$. & 1 & 2 & 3 & 4 & 5 & 6 \\
\hline 1. Spiritual Modeling & $72.81(12.14)$ & & & & & & \\
\hline 2. Spirituality & $53.17(9.65)$ & $\begin{array}{l}.559 * \\
*\end{array}$ & & & & & \\
\hline 3. Mindfulness & $31.24(5.67)$ & $\begin{array}{l}.168^{*} \\
*\end{array}$ & $.21^{* *}$ & & & & \\
\hline 4. Forgiveness & $84.28(15.20)$ & $\begin{array}{l}.167^{*} \\
*\end{array}$ & $.22 * *$ & $.51 * *$ & & & \\
\hline 5. Hope & $48.66(8.13)$ & $\begin{array}{l}.240 * \\
*\end{array}$ & $\begin{array}{l}.341 * \\
*\end{array}$ & $.516 * *$ & $.405^{* *}$ & & \\
\hline 6. College Self-Efficacy & $138.47(31.41)$ & $\begin{array}{l}.243 * \\
*\end{array}$ & $.32 * *$ & $.524^{* *}$ & $.385^{* *}$ & $.598 * *$ & \\
\hline 7. Perspective-taking & $21.05(5.33)$ & $.09 * *$ & .021 & $.211^{* *}$ & $.308 * *$ & $.301^{* *}$ & $\begin{array}{l}.182^{*} \\
*\end{array}$ \\
\hline
\end{tabular}
Note: ${ }^{* *}=p<.01$.

\section{Mediation Analyses}

\section{Spirituality as a mediator}

The direct path from environmental support from spiritual models to college self-efficacy was significant ( $\beta=.08, p=.17$ ) (See figure 1 ). The path from environmental support from spiritual models to spirituality was significant $\left(\beta=.56, p<.001, R^{2}=.314, p<.001\right)$ and the path from spirituality to college self-efficacy was significant $\left(\beta=.28, p<.001, R^{2}=.109, p=.001\right)$. See Table 2 and Figure 1. The model fit was just-identified, $\chi^{2}(0)=0, p<0.001$; RMSEA $<.001,90 \% \mathrm{Cl}$ [0.20-0.26]; CFI = 1.00; TLI = 1.00 .

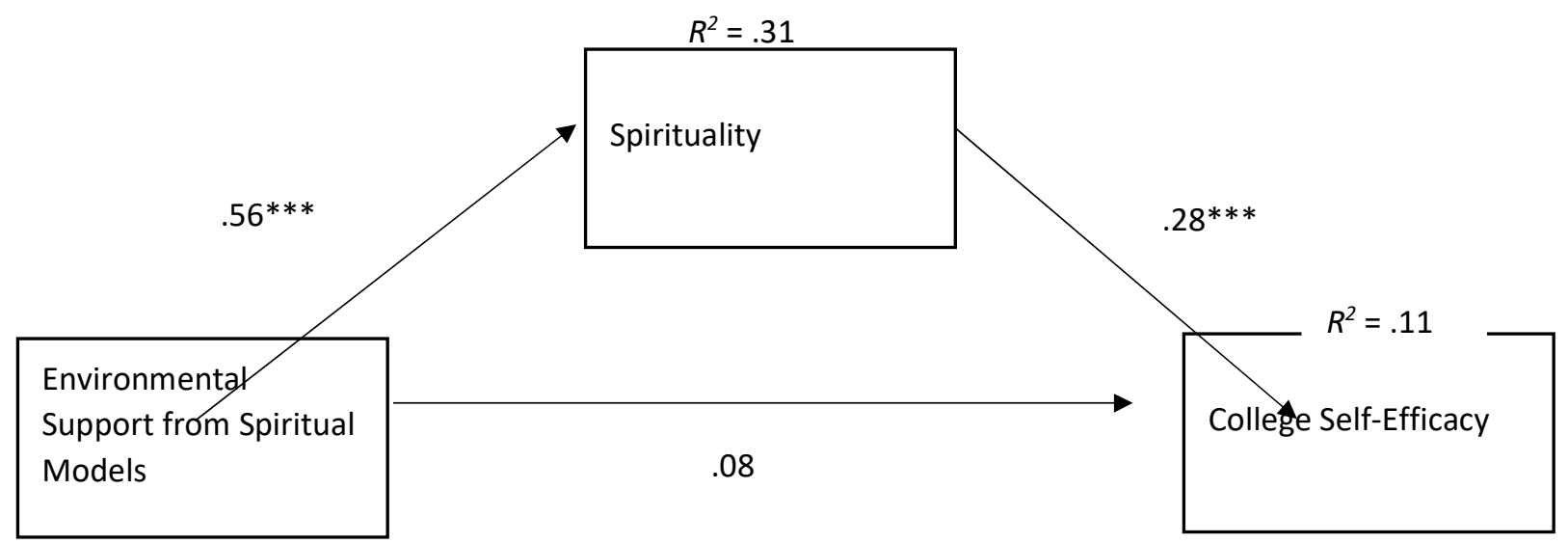

Figure 1. Mediation Path: Spirituality. Note. ${ }^{* * *}=p \leq .001$

\section{Mindfulness as a mediator}

The direct path from environmental support from spiritual models to college self-efficacy was significant $(\beta=.16, p=.001)$, and the bootstrap confidence intervals for the direct effect were significant ( $\beta=.16$; Cls [.05-.24], [.05-.24], [.06-.24], [.05-.24], and [.05-.24]). The indirect path 
was also significant, with environmental support from spiritual models to mindfulness being significant $\left(\beta=.16, p<.001, R^{2}=.026, p=.171\right)$. In turn, the path from mindfulness to college self-efficacy displayed significance $\left(\beta=.50, p<.001, R^{2}=.299, p<.001\right)$. See Table 2 and Figure 2. The model fit was just-identified, $\chi^{2}(0)=0, p=1.00 ; \mathrm{RMSEA}<.001,90 \% \mathrm{Cl}[0.23-0.29] ; \mathrm{CFI}=$ $1.00 ; \mathrm{TLI}=1.00$.

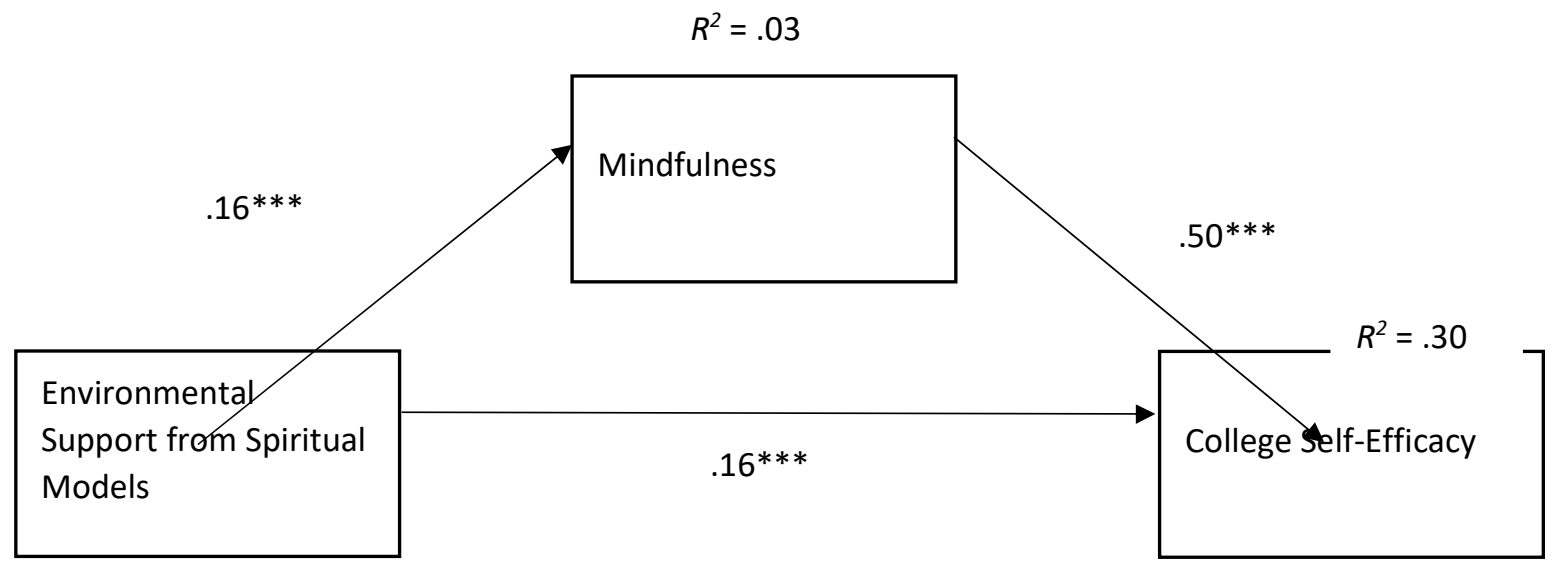

Figure 2. Mediation Path: Mindfulness. Note. ${ }^{* *}=p \leq .01, * * *=p \leq .001$.

\section{Forgiveness as a mediator}

The direct path from environmental support from spiritual models to college self-efficacy was significant $(\beta=.18, p=.001)$, and the bootstrap confidence intervals for the direct effect were significant ( $\beta=.18 ; 95 \% \mathrm{Cls}$ [.07-.27], [.07-.27], [.07-.27], [.07-.27], and [.07-.27]). The indirect path from environmental support from spiritual models to college self-efficacy was also significant with the path from environmental support from spiritual models to forgiveness being significant $\left(\beta=.16, p<.001, R^{2}=.097\right)$. In turn, the path from forgiveness to college self-efficacy displayed significance $\left(\beta=.36, p<.001 ; R^{2}=.179, p<.001\right)$. See Table 2 and Figure 3 . The model fit was just-identified, $\chi^{2}(0)=0, p=1.00 ;$ RMSEA <.001, 90\% Cl [0.14-0.21]; CFI = 1.00; TLI = 1.00 .

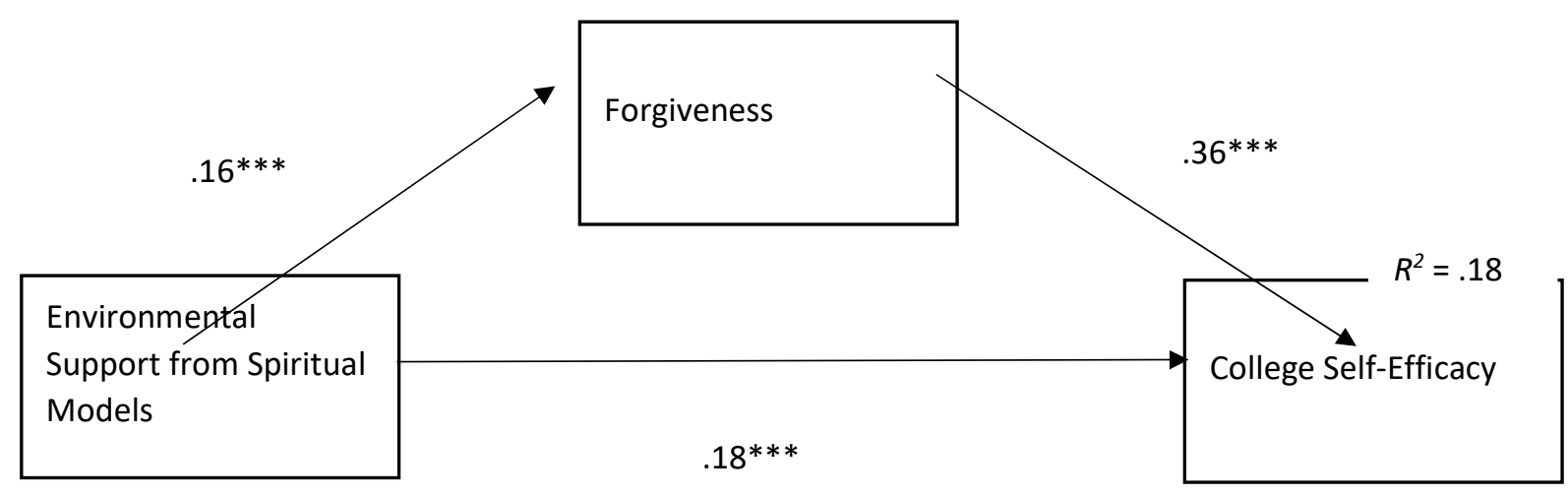

Figure 3. Mediation Path: Forgiveness. $\quad R^{2}=.10 \quad$ Note. $* * *=p \leq .001$. 


\section{Hope as a mediator}

The direct path from environmental support from spiritual models to college self-efficacy was significant $(\beta=.10, p<.03)$, and four out of five bootstrap confidence intervals for the direct effect ( $\beta=.10 ; 95 \%$ Cls [.00-.18], [.00-.18], [.00-.18], [.00-.18], [-.004-.17]) were significant. The indirect path from environmental support from spiritual models to college self-efficacy through the mediator hope was significant, with environmental support from spiritual models to hope being significant ( $\beta=.24, p<.001, R^{2}=.055, p=.009$ ). In turn, the path from hope to college self-efficacy displayed significance $\left(\beta=.57, p=.001 ; R^{2}=.369, p<.001\right)$. See Table 2 and Figure 4. The model fit was just-identified, $\chi^{2}(0)=0, p=1.00 ; \mathrm{RMSEA}<.001,90 \% \mathrm{Cl}[0.24-0.30] ; \mathrm{CFI}=$ $1.00 ; \mathrm{TLI}=1.00$.

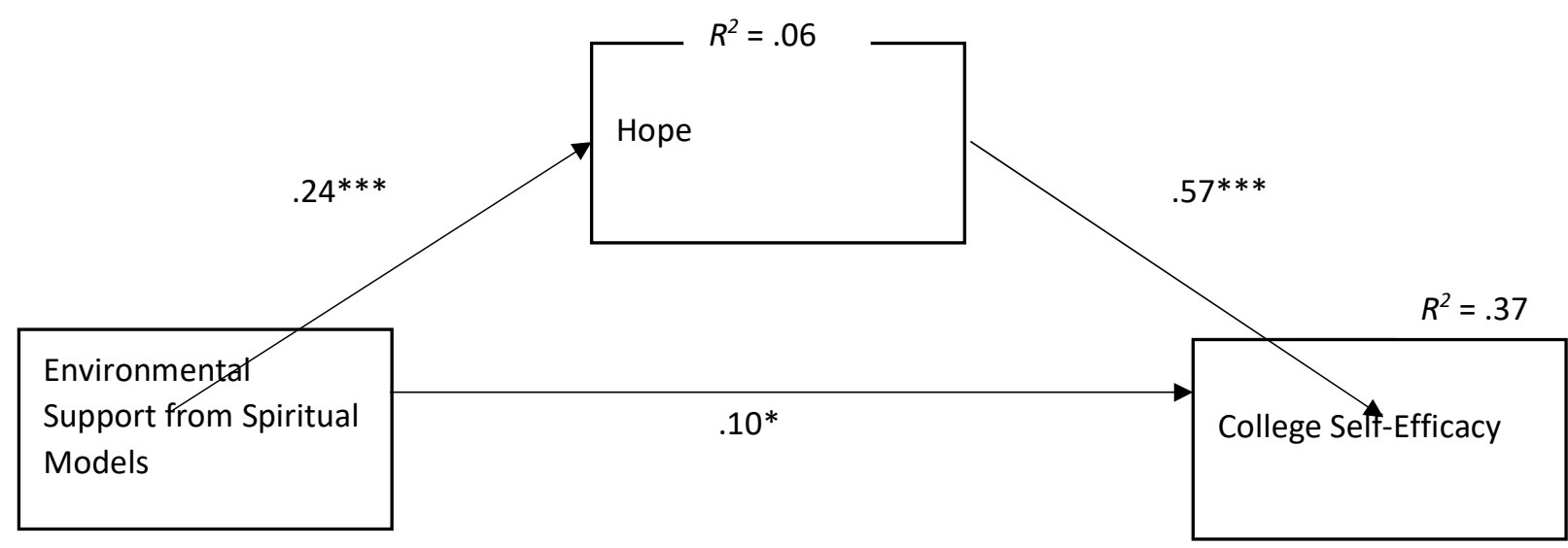

Figure 4. Mediation Path: Hope. Note. ${ }^{*}=p \leq .05, * * *=p \leq .001$

\section{Moderation Analysis}

Perspective-taking did not moderate the path from environmental support from spiritual models to any of the trait variables in the paths from environmental support from spiritual models to college self-efficacy. Four separate moderated mediation paths were run, building on the mediation paths in the previous sections. The moderated mediation model with perspective-taking as the moderator and spirituality as the mediator had an inadequate model fit, $\chi 2(2)=14.401, p<0.001 ;$ RMSEA = .130, 90\% Cl [0.07-0.20]; CFI = .933; TLI = .764, possibly due to the non-significant relationship between perspective-taking and spirituality $(\beta=.08, p=$ .83). The moderating effect of perspective-taking on the relationship between environmental support of a spiritual model and spirituality was non-significant $(\beta=-.14, p=.75)$. The moderated mediation model with perspective-taking as the moderator and mindfulness as the mediator had an inadequate model fit $\chi^{2}(2)=19.447, p<0.001$; RMSEA $=.123,90 \% \mathrm{Cl}[0.07-$ $0.18] ; \mathrm{CFI}=.90 ; \mathrm{TLI}=.77$, possibly due to the non-significant relationships between environmental support from a spiritual model on mindfulness ( $\beta=.06, p=.84)$ and perspectivetaking on mindfulness $(\beta=.01, p=.99)$. The moderating effect of perspective-taking on the relationship between environmental support from a spiritual model and mindfulness was non- 
Table 2. Direct, indirect and total effects for environmental support from spiritual models and mediators on college self-efficacy

\begin{tabular}{|c|c|c|c|c|c|c|c|c|c|c|c|c|c|c|c|}
\hline \multirow[b]{2}{*}{ Effect Name } & \multicolumn{3}{|c|}{ MI1 } & \multicolumn{3}{|c|}{ MI2 } & \multicolumn{3}{|c|}{ MI3 } & \multicolumn{3}{|c|}{ MI4 } & \multicolumn{3}{|c|}{ MI5 } \\
\hline & Est. & SE & $95 \% \mathrm{BCI}$ & Est. & SE & $95 \% \mathrm{BCI}$ & Est. & SE & $95 \%$ BCI & Est. & $\mathrm{SE}$ & $95 \% \mathrm{BCI}$ & Est. & SE & $95 \% \mathrm{BCI}$ \\
\hline Spirituality & & & & & & & & & & & & & & & \\
\hline Total Effect & $.24 * * *$ & .05 & $(.13, .33)$ & $.24 * * *$ & .05 & $(.13, .33)$ & $.24 * * *$ & .05 & $(.13, .33)$ & $.24 * * *$ & .05 & $(.13, .33)$ & $.24 * * *$ & 0.05 & $(.13, .33)$ \\
\hline Direct Effect & .08 & .06 & $(-.05, .19)$ & .08 & .06 & $(-.05, .19)$ & .08 & .06 & $(-.04, .19)$ & .08 & .06 & $(-.05, .19)$ & .08 & 0.06 & $(-.05, .19)$ \\
\hline $\begin{array}{l}\text { Indirect Effect } \\
\text { Mindfulness }\end{array}$ & $.16^{* * * *}$ & .03 & $(.10, .22)$ & $.16^{* * * *}$ & .03 & $(.10, .23)$ & $.16^{* * * *}$ & .03 & $(.09, .22)$ & $.16^{* * * *}$ & .03 & $(.09, .22)$ & $.16^{* * * *}$ & 0.03 & $(.10, .22)$ \\
\hline Total Effect & $.24 * * *$ & .05 & $(.13, .33)$ & $.24 * * *$ & .05 & $(.13, .33)$ & $.24 * * *$ & .05 & $(.13, .33)$ & $.24 * * *$ & .05 & $(.13, .33)$ & $.24 * * *$ & .05 & $(.13, .33)$ \\
\hline Direct Effect & $.16^{* * * *}$ & .05 & $(.05, .24)$ & $.16^{* * *}$ & .05 & $(.05, .24)$ & $.16^{* * *}$ & .05 & $(.06, .24)$ & $.16^{* * *}$ & .05 & $(.05, .24)$ & $.16^{* * *}$ & .05 & $(.05, .24)$ \\
\hline $\begin{array}{l}\text { Indirect Effect } \\
\text { Forgiveness }\end{array}$ & $.08 * *$ & .03 & $(.02, .14)$ & $.08 * *$ & .03 & $(.02, .14)$ & $.08 * *$ & .03 & $(.02, .14)$ & $.08 * *$ & .03 & $(.02, .14)$ & $.08 * *$ & .03 & $(.02, .14)$ \\
\hline Total Effect & $.24 * * *$ & .05 & $(.13, .33)$ & $.24 * * *$ & .05 & $(.13, .33)$ & $.24 * * *$ & .05 & $(.13, .33)$ & $.24 * * *$ & .05 & $(.13, .33)$ & $.24 * * *$ & .05 & $(.13, .33)$ \\
\hline Direct Effect & $.18 * * *$ & .05 & $(.07, .27)$ & $.18 * * *$ & .05 & $(.07, .27)$ & $.18 * * *$ & .05 & $(.07, .27)$ & $.18 * * *$ & .05 & $(.07, .27)$ & $.18 * * *$ & .05 & $(.07, .27)$ \\
\hline $\begin{array}{l}\text { Indirect Effect } \\
\text { Hope }\end{array}$ & $.06 * *$ & .02 & $(.03, .10)$ & $.06 * *$ & .02 & $(.03, .10)$ & $.06 * *$ & .02 & $(.03, .10)$ & $.06 * *$ & .02 & $(.02, .10)$ & $.06 * *$ & .02 & $(.03, .10)$ \\
\hline Total Effect & $.24 * * *$ & .05 & $(.13, .33)$ & $.24 * * *$ & .05 & $(.13, .33)$ & $.24 * * *$ & .05 & $(.13, .33)$ & $.24 * * *$ & .05 & $(.13, .33)$ & $.24 * * *$ & .05 & $(.13, .33)$ \\
\hline Direct Effect & $.10^{*}$ & .05 & $(.00, .18)$ & $.10^{*}$ & .05 & $(.00, .18)$ & $.10^{*}$ & .05 & $(.00, .18)$ & $.10^{*}$ & .05 & $(.00, .18)$ & .10 & .05 & $(-.004, .17)$ \\
\hline Indirect Effect & $.13 * * *$ & .03 & $(.08, .19)$ & $.14 * * *$ & .03 & $(.08, .19)$ & $.14 * * *$ & .03 & $(.08, .19)$ & $.14 * * *$ & .03 & $(.08, .19)$ & $.14 * * *$ & .03 & $(.08, .19)$ \\
\hline
\end{tabular}

Note: $\mathrm{MI}=$ Multiple Imputation. Est.= Effect Estimate. $\mathrm{SE}=$ Effect Standard Error. $95 \% \mathrm{BCI}=$ for $95 \%$ bootstrapping confidence interval. $*=p<.05, * *=p<.01, * * *=p \leq .001$, for normal theory test for effect estimate. 
significant $(\beta=.24, p=.66)$. The moderated mediation model with perspective-taking as the moderator and forgiveness as the mediator had an adequate model fit $\chi^{2}(2)=5.323, p=.07$; RMSEA $=.067,90 \% \mathrm{Cl}[0.00-0.14] ; \mathrm{CFI}=.97 ; \mathrm{TLI}=.90$. The moderating effect of perspectivetaking on the relationship from environmental support from a spiritual model to forgiveness was non-significant $(\beta=.56, p=.11)$. The moderated mediation model with perspective-taking as the moderator and hope as the mediator had an overfit model $\chi^{2}(2)=.49, p=.78$; RMSEA $=$ $.00,90 \% \mathrm{Cl}[0.00-0.07] ; \mathrm{CFI}=1.00 ; \mathrm{TLI}=1.025$, possibly due to the non-significant relationship of perspective-taking and hope $(\beta=.62, p=.08$ ). The moderating effect of perspective-taking on the relationship from environmental support from a spiritual model to hope was nonsignificant $(\beta=-.42, p=.32)$.

Discussion

Participants from the Southeastern Christian university reported more support from spiritual models, higher spirituality, and higher college self-efficacy than participants from the Southeastern public university. The group differences are understandable, considering the culture of the religiously affiliated university centers around spiritual practices, which can be learned through response facilitation (Schunk 2020). Additionally, students from the religious university may encounter more individuals who serve as spiritual models, such as faculty and staff, in addition to clergy. Similarly, associations have been found between religious support and religiosity related to various types of self-efficacy, which provides support for the higher group average in college self-efficacy for the private religious university as opposed to the public university (Abdel-Khalek and Lester 2017; Duffy and Lent 2008). In contrast, the current study showed that participants from the Southeastern public university reported significantly higher levels of perspective-taking than participants from the private university. Participants from the Christian university may be constantly exposed to one type of ideology that is expected to be taken literally; whereas students in the public university are likely to encounter a vast array of spiritual beliefs and practices. Experiencing diversity in the university setting may lend itself toward a more symbolic interpretation of spiritual contents rather than a literal one, which has been associated with higher perspective-taking (Duriez 2004).

According to the model of normative life satisfaction and supporting evidence by Lent and colleagues (2007), having social support can result in positive outcomes. The current study sought to determine if maintaining environmental support from spiritual models is beneficial for college self-efficacy, a known contributor to success in college (Brady-Amoon and Fuertes 2010; Gore, Leuwerke, and Turley 2005; Gore 2006; Zajacova, Lynch, and Epsenshade 2005). The first contribution of the current study was the correlation found between environmental support from spiritual models and college self-efficacy. In the model by Lent and colleagues (2007), positive affect and healthy traits mediated the relationship from social support to positive outcomes. This framework inspired the current study of the impact of environmental support from spiritual models to modifiable traits of spirituality, mindfulness, forgiveness, and 
hope. In the following sections, mediation paths were discussed separately to emphasize the impact of each variable and model impact on college self-efficacy.

\section{Behavioral Mediating Trait}

The indirect path from environmental support from spiritual models to college self-efficacy through the mediator spirituality was supported. Among the paths from environmental support from spiritual models to the mediators, environmental support from spiritual models accounted for the most variance in spirituality, at 31 percent of the variance in spirituality explained by environmental support from spiritual models (see Figure 3). Considering 90.1 percent of participants endorsed Christianity as their religion, and some of the behaviors involved in Christian spirituality can be learned by response facilitation (Schunk 2020) such as attending services, reading sacred texts, and participating in scripture and prayer groups. Such overt practices may be more easily demonstrated, learned, and remembered when reporting on a survey, which may also account for the moderate variance in spirituality explained by environmental support from spiritual models as opposed to the small percent variance in the cognitive mediators explained by environmental support form spiritual models.

In turn, the path from spiritual modeling to college self-efficacy through spirituality was weak, with only ten percent of the variance in college self-efficacy explained by the path. Perhaps the behavioral and transcendent aspects of spirituality have little to do with the mindset of a college student who is completing schoolwork and managing social situations.

\section{Cognitive Mediating Traits}

The path from environmental support from spiritual models to the cognitive mediators, mindfulness, forgiveness, and hope, were each significant with small effect sizes, indicating that college students may not learn to be mindful, forgiving, and hopeful as readily as they learn the practices associated with spirituality. Mindfulness has historical roots in Buddhism, and spiritual models in other religions are skeptical of explicitly teaching the construct (Symington and Symington 2012). Although previous findings indicate that college students can develop mindfulness through explicit instruction (Shapiro et al. 2008), the current findings suggested that mindfulness may vary only slightly based on environmental support from a spiritual model. Regarding forgiveness, the current study found that environmental support from spiritual models may only account for about ten percent of the variance in forgiveness (see figure 5) and six percent of the variance in hope. Such small variance may be due to reluctance of spiritual models to self-disclose hurtful situations where forgiveness has been extended to or provided by another person. Self-disclosure is important between models and learners, but disclosure may be rightly withheld if it would be harmful to another person within the community (Palmberg and Scandrette 1977). Learners may also limit disclosure of perceived offenses or collegiate challenges to a spiritual model, limiting the model's awareness that forgiveness and hope need to be taught and modeled to the learner. The extent to which models support mindful, forgiving, and hopeful thinking may depend on how much interaction the college 
student has with the community spiritual model and how much of the challenges of college life are disclosed to the model.

Within the path, mindfulness accounted for 30 percent of the variance in college selfefficacy, forgiveness accounted for 18 percent of the variance in college self-efficacy, and hope accounted for 36 percent of the variance in college self-efficacy. Previous associations between mindfulness and academic self-efficacy in the face of failure support the directionality of mindfulness to academic self-efficacy (Hanley et al. 2015; Keye and Pidgeon 2013), but college students who can view situations non-judgmentally, be present with their thoughts and feelings, and act with awareness may perceive themselves as more socially competent. The current findings indicated that although the effect size is small, forgiveness was associated with total college self-efficacy, perhaps because forgiveness of oneself and situations is helpful for decreasing the impact of prior academic failures, while forgiveness of others may mitigate conflict in the social and roommate aspects of college self-efficacy. The path from hope to college self-efficacy reflected the relationship and directionality established in previous research (Feldman, Davidson, and Margalit 2015; Feldman and Kubota 2015; Feldman et al. 2016; Macaskill and Denovan 2013). Individuals who are high in hope are able to consider alternative paths to reaching goals and may be less likely to have future plans or successes derailed by stress over academic failures.

\section{Perspective-taking as a Moderator}

In this study, perspective-taking was correlated with small to medium effect sizes for mindfulness, forgiveness, and hope, but not with spirituality. Spirituality is partially behavioral and partially a subjective view of transcendent reality, neither of which require perspectivetaking to develop. However, mindfulness involves non-judgment, non-reactivity, and acting with awareness, and the perspectives of others may be one important factor for gaining awareness and offering intentional responses in social situations. The current study was the first study known to associate perspective-taking with mindfulness. Forgiveness involves cultivating an empathic stance toward an offender and perspective-taking is the cognitive aspect of empathy, making the positive correlation understandable. Similarly, hope is developed in relationships with others, who initially share their views of children's abilities and paths to solving problems. As children grow and encounter new challenges, returning to the perspectives of supportive caregivers can stimulate agency and pathways thinking, supporting a positive correlation between perspective-taking and hope.

However, perspective-taking was not found to moderate the paths between environmental support from spiritual models and any of the mediators. Moderators are variables that are intended to increase the impact of the explanatory variable on the response variable, or in this case, the mediators. Mediation analyses revealed that environmental support from spiritual models only slightly accounted for the variance in mindfulness, forgiveness, and hope, perhaps due to the lack of self-disclosure by the model or the learner. If the model isn't 
sharing personal stories with the college student, the student may not have cause to inquire about the cognitive states of the model, and the student may not have cause to take the model's perspectives. If college students believe they can learn everything they need to gain from a spiritual model by imitating the model's behaviors, they may not expend the time and energy needed to disclose and seriously consider the sentiments behind the model's actions and reported experiences. Alternatively, college students may believe they are taking away accurate representations of what spiritual models intend for them to learn, but what is gleaned from the spiritual model might not be interpreted correctly without proper perspective-taking. In these cases, college students may miss opportunities to cultivate mindful living, forgiveness, and hopeful thinking that could increase college self-efficacy.

\section{CONCLUSIONS}

Environmental support from spiritual models may be more readily available at Southeastern Christian universities. Such support plays a role in development of partially behavioral traits such as the aspect of spirituality that involves practice than spiritual support plays in mindfulness, forgiveness, and hope maintenance during college. In turn, models with primarily cognitive mediators of mindfulness, forgiveness, and hope accounted for more of the variance in college self-efficacy than the model with spirituality as a mediator. Finally, perspective-taking was not a moderator of any of the models, indicating that if spiritual models are not looked to for developing cognitive traits of mindfulness, forgiveness, and hope, considering models' perspectives was also not important to the learner. Regarding spirituality, important behavioral components can be acquired from spiritual models through response facilitation rather than by taking the perspective of the model, and spirituality is less important for college self-efficacy. Overall, the study provides support for part of Lent's et al. (2007) model of normative life satisfaction by supporting the path from social support, in this case spiritual, to positive outcomes, in this case college self-efficacy through healthy trait mediators.

\section{Implications}

Implications of the study are two-fold. First, identifying traits that lead to college self-efficacy can help university staff, at Christian and public universities, promote practices that will lead to achievement and persistence. Previous studies indicate that spirituality, mindfulness, forgiveness, and hope are malleable traits that can be developed through social interactions (Davidson, Feldman, and Margalit 2012; Kiken, et al. 2015; Luskin, Ginzburg, and Thoresen 2005; Oman et al. 2007), and the current study provided evidence that learning spirituality, mindfulness, forgiveness, and hope from a spiritual model did account for variance in college self-efficacy.

Next, the current study holds implications regarding spiritual changes that take place in emerging adulthood (Arnett 2000). It is known that college students report decreases in religious practices such as attending services, but emerging adults also report increases in religious beliefs and religious importance (Lefkowitz 2005). Encountering different spiritual 
worldviews in college, paired with the individualistic, self-focused quality of emerging adulthood, may result in a more personal and diverse set of values and spiritual beliefs (Arnett 2000; Gutierrez and Park 2015; Lefkowitz 2005). However, previous research suggests welladjusted college students engage in religious practices or have spiritual beliefs in a transcendent reality that are associated with more positive views of the self than groups of students characterized predominantly by externalized, risky behaviors or internalized, emotional distress (Nelson and Padilla-Walker 2013). Additionally, Oman and Thoresen (2003) contend that spiritual beliefs will be considered valuable if they transfer into success in the secular world. The current findings that traits learned from a spiritual model were beneficial in a collegiate outcome may discourage students from abandoning faith, and encourage an evolving, eclectic, and useful spiritual worldview that contributes to positive development (Arnett 2000). Students in Southeastern public universities report greater perspective-taking, which Christian universities can use to guide efforts toward developing perspective-taking among students although it did not influence the path.

\section{Limitations and Future Directions}

Convenience sampling was used to gain participants in psychology and educational psychology courses. Also, most participants endorsed Christianity as their religion. The high percentage of Christians at the public university was unexpected, considering that diversity and inclusion is part of the culture of the public university and spiritual diversity was part of the rationale for the large sample from two universities. Future studies could include more participants with varied religious preferences.

Future qualitative studies could examine the types of disclosures learners report making as well as disclosures reportedly made by the model, and how these disclosures influence the development of spirituality, mindfulness, forgiveness and hope. Additionally, because learners may not take away accurate interpretations of information disclosed by a spiritual model, qualitative studies could examine the spiritual model's perspective of what the learner could have gained from an exchange compared to what the learner reports gleaning from the spiritual model.

\section{REFERENCES}

Abdel-Khalek, Ahmed, and David Lester. "The Association Between Religiosity, Generalized Self-Efficacy, Mental Health, and Happiness in Arab College Students. 2017. Personality and Individual Differences. 109: 12-16. https://doi.org/10.1016/j.paid.2016.12.010. Arnett, Jeffrey Jensen. "Emerging Adulthood: A Theory of Development from the Late Teens Through the Twenties." 2000. American Psychologist. 55, no. 5: 469-480.

https://doi.org/10.1037//0003-066X.55.5.469.

Babyak, Michael A., Charles Richard Snyder, and Lauren Yoshinobu. "Psychometric Properties 
of the Hope Scale: A Confirmatory Factor Analysis." 1993. Journal of Research in Personality. 27, no. 2: 154-169. https://doi.org/10.1006/jrpe.1993.1011.

Brady-Amoon, Peggy, and Jairo N. Fuertes. "Self-Efficacy, Self-Rated Abilities, Adjustment, and Academic Performance." 2011. Journal of Counseling and Development 89: 431438.

Davidson, Oranit B., David B. Feldman, and Malka Margalit. “A Focused Intervention for $1^{\text {st }}$ Year College Students: Promoting Hope, Sense of Coherence, and Self-Efficacy." 2012. Journal of Psychology: Interdisciplinary and Applied. 146, no. 3 (March): 333-352. https://doi.org/10.1080/00223980.2011.634862.

Davis, Mark H. "Measuring Individual Differences in Empathy: Evidence for a Multidimensional Approach." 1983. Journal of Personality and Social Psychology. 44, no. 1 (July): 113-126.

Duffy, Ryan D., and Robert W. Lent. "Relation of Religious Support to Career Decision SelfEfficacy in College Students." 2008. Journal of career assessment 16, no. 3: 360-369, https://doi.org/10.1177/1069072708317382.

Duriez, Bart. “Are Religious People Nicer People? Taking a Closer Look at the ReligionEmpathy Relationship." 2004. Mental Health, Religion, and Culture. 7, no. 3: 249-254, https://doi.org/10.1080/13674670310001606450.

Feldman, David B., Oranit B. Davidson, Shiri Ben-Naim, Etai Maza, and Malka Margalit. "Hope as a Mediator of Loneliness and Academic Self-Efficacy Among Students With and Without Learning Disabilities During the Transition to College." 2016. Learning Disabilities Research and Practice, 31, no. 2: 63-74 https://doi.org/10.1111/idrp.12094.

Feldman, David B., Oranit B. Davidson, and Malka Margalit. "Personal Resources, Hope, and Achievement Among College Students: The Conservation of Resources Perspective." 2015. Journal of Happiness Studies 16: 543-560. https://doi.org/10.1007/s10902-0149508-5.

Feldman, David B., and Maximilian Kubota "Hope, Self-Efficacy, Optimism, and Academic Achievement: Distinguishing Constructs and Levels of Specificity in Predicting College Grade-Point Average." 2015. Learning and Individual Differences. 37: 210-216. doi.org/10.1016/j.lindif.2014.11.022.

Feldman, Greg, Adele Hayes, Sameet Kumar, Jeffrey Greeson, and Jean-Philippe Laurenceau. "Mindfulness and Emotion Regulation: The Development and Initial Validation of the Cognitive and Affective Mindfulness Scale-Revised (CAMS-R)." 2007. Journal of Psychopathology and Behavioral Assessment. 29, no. 3 (July): 177-189. https://doi.org/10.1007/s10862-006-9035-8.

Gore, Paul A. "Academic Self-Efficacy as a Predictor of College Outcomes: Two Incremental Validity Studies." 2006. Journal of Career Assessment. 14, no. 1 (February), https://doi.org/10.1177/1069072705281367

Gore, Paul A., Wade C. Leuwerke, and Sarah E. Turley. "A Psychometric Study of the College 
Self-Efficacy Inventory." 2005. Journal of College Student Retention. 7, no. 3-4

(November): 227-244. https://doi.org/10.2190/5CQF-F3P4-2QAC-GNVJ.

Gutierrez, Ian A., and Crystal L. Park. "Emerging Adulthood, Evolving Worldviews: How Life

Events Impact College Students' Developing Belief Systems." 2015. Emerging Adulthood

3, no. 2: 85-97. https://doi.org/10.1177/2167696814544501

Hanley, Adam W., Mohammed H. Palejwala, Robert T. Hanley, Angela I. Canto, and Eric L.

Garland. "A Failure in Mind: Dispositional Mindfulness and Positive Reappraisal as

Predictors of Academic Self-Efficacy Following Failure." 2015. Personality and Individual

Differences. 86 (November): 332-337. https://doi.org/10.1016/j.paid.2015.06.033.

Keye, Michelle D., and Aileen M. Pidgeon. "An Investigation of the Relationship Between

Resilience, Mindfulness, and Academic Self-Efficacy." 2013. Open Journal of Social

Sciences. 1, no. 6 (November): 1-4. https://doi.org/10.4236/jss.2013.16001.

Kiken, Laura G., Eric L. Garland, Karen Bluth, Olafur S. Palsson, and Susan A. Gaylord. "From

a State to a Trait; Trajectories of State Mindfulness in Meditation During Intervention

Predict Changes in Trait Mindfulness." 2015. Personality and Individual Differences.

81(July): 41-46. https://doi.org/10.1016/j.paid.2014.12.044.

Lefkowitz, Eva S. "Things have Gotten Better": Developmental Changes Among Emerging

Adults After the transition to university." 2005. Journal of Adolescent Research, 20, no.

1 (January): 40-63. https://doi.org/10.1177/0743558404271236.

Lent, Robert. W. "Toward a unifying theoretical and practical perspective on well-being and

psychosocial adjustment." 2004. Journal of Counseling Psychology 51, no. 4: 482-509, https:/doi.org/10.1037/0022-0167.51.4.482.

Lent, R. W., Maria do Céu Taveira, Hung-Bin Sheu and Daniel Singley. "Social cognitive

predictors of academic adjustment and life satisfaction in Portuguese college students:

A longitudinal analysis." 2009. Journal of Vocational Behavior 74: 190-198.

http://doi.org/10.1016/j.jvb.2008.12.006.

Lent, Robert W., Daniel Singley, Hung-Bin Sheu, Kathy A. Gainor, Bradley R. Brenner, Dana

Treistman, and Lisa Ades. "Social cognitive predictors of domain and life satisfaction:

Exploring the theoretical precursors of subjective well-being." 2005. Journal of

Counseling Psychology 52, no. 3: 429-442. http://doi.org/10.1037/0022-0167.52.3.429

Lent, Robert W., Daniel Singley, Hung-Bin Sheu, Janet A. Schmidt, and Linda C. Schmidt.

"Relation of social-cognitive factors to academic satisfaction in engineering students."

2007. Journal of Career Assessment 15, no. 1 (February): 87-97.

https://doi.org/10.1177/1069072706294518.

Luskin, Frederic M., Karni Ginzburg, and Carl E. Thoresen. "The efficacy of forgiveness intervention in college age adults: Randomized controlled study." 2005. Humboldt Journal of Social Relations. 29, no. 2: 163-184.

Macaskill, Ann, and Andrew Denovan. "Developing autonomous learning in first year university 
students using perspectives from positive psychology." 2013 Studies in Higher Education 38, no. 1: 124-142.

Nelson, Larry J., and Laura M. Padilla-Walker. "Flourishing and floundering in emerging adult college students." 2013. Emerging Adulthood. 1, no. 1: 67-78. https://doi.org/10.1177/2167696812470938.

Oman, Doug. "Spiritual modeling and the social learning of spirituality and religion." 2013. In K. I. Pargament, J. J. Exline, and J. W. Jones (Eds.), APA handbook of psychology, religion, and spirituality (Volume 1): context theory, and Research. 1: 187-204. https://doi.org/10.1037/14045-010.

Oman, Doug, Shauna L. Shapiro, Carl E. Thoresen, Tim Flinders, Joseph D. Driskill, and Thomas G. Plante. "Learning from spiritual models and meditation: A randomized evaluation of a college course." 2007. Pastoral Psychology 54: 473-493. https://doi.org/10.1007/s11089-006-0062-x.

Oman, Doug, and Carl E. Thoresen. "Spiritual modeling: A key to spiritual and religious growth?" 2003. The International Journal for the Psychology of Religion. 13, no. 3 (November): 149-165. http://doi.org/10.1207/S15327582IJPR1303_01

Oman, Doug, Carl E. Thoresen, Crystal L. Park, Phillip R. Shaver, Ralph W. Hood, and Thomas G. Plante. "How does one become spiritual? The spiritual modeling inventory of life environments." 2009. Mental Health, Religion, and Culture. 12, no. 5(July): 427-456, https://doi.org/10.1080/13674670902758257.

Palmberg, Lynn, and Onas Scandrette. "Self-disclosure in biblical perspective." 1977. Journal of Psychology and Theology. 5, no. 3: 209-219. https://doi.org/10.1177/009164717700500303.

Piedmont, Ralph. L., M. Christine Kennedy, Martin F. Sherman, Nancy C. Sherman, and Joseph E. G. Williams. "A psychometric evaluation of the assessment of spirituality and religious sentiments (ASPIRES) scale: Short form." 2008. Research in the Social Scientific Study of Religion 19:163-182.

Schunk, Dale H. Learning theories: An educational perspective. ( $8^{\text {th }}$ ed.). 2020. New York, NY: Pearson.

Shapiro, Shauna L., Doug Oman, Carl E. Thoresen, Thomas G. Plante, and Tim Flinders. "Cultivating mindfulness: Effects on well-being" 2008. Journal of Clinical Psychology 64, no. 7: 840-862. https://doi.org/10.1002/jclp.20491.

Solberg, V. Scott, Karen O'Brien, Pete Villareal, Richard Kennel, and Betsy Davis. "Selfefficacy and Hispanic college students: Validation of the College Self-Efficacy Instrument." 1993. Hispanic Journal of Behavioral Sciences 15, no.1 (February): 80-95.

Symington, Scott. H., and Melissa F. Symington. "A Christian model of mindfulness: Using mindfulness principles to support psychological well-being, value-based behavior, and the Christian spiritual journey." 2012. Journal of Psychology and Christianity 31 no. 1: 71-77. ISSN 0733-4273. 
Thompson, Laura Y., C. R. Snyder, Lesa Hoffman, Scott T. Michael, Heather N. Rasmussen, Laura S. Billings, Laura Heinze, Jason E. Neufeld, Hal S. Shorey, Jessica C. Roberts, and Danae E. Roberts. "Dispositional forgiveness of self, others, and situations." 2005. Journal of Personality 73, no. 2 (April): 313-360. https://doi.org/10.1111/j.14676494.2005.00311.x.

Zajacova, Anna, Scott M. Lynch, and Thomas J. Espenshade. "Self-efficacy, stress, and academic success in college." 2005. Research in Higher Education. 46, no. 6 (September): 677-706. https://doi.org/10.1007/s11162-004-4139-z. 